\title{
Non-martensitic Needle-like Structures on Ni-Ti Alloys - Occurrence and Origin
}

\author{
A. Undisz ${ }^{\mathrm{a} 1}$, M. Rettenmayr ${ }^{1}$, M. Wilke ${ }^{2}$ and L. Spie $\beta^{2}$ \\ ${ }^{1}$ Department of Metallic Materials, Friedrich-Schiller-University Jena, 07743 Jena, Germany \\ ${ }^{2}$ Department of Micro \& Nanotechnology, Technical University Ilmenau, 98684 Ilmenau, Germany
}

\begin{abstract}
In the present work the occurrence of needle-like structures that are observed on martensitic and austenitic $\mathrm{NiTi}$ after metallographic preparation and etching is described. The investigations show that the needle-like structures form in less than 10s during the etching process if solutions containing HF are applied. The needle-like structures look very similar to martensitic structures. Hence it is tempting to interpret them as martensite. Distinguishing the structures from martensite is not straightforward since standard analysis e.g. by EDX does not yield any differences in chemical composition of the needle-like structures and NiTi. Application of surface sensitive methods like grazing incidence X-ray diffraction clearly shows that the needle-like structures are different from martensitic structures of NiTi. In the present study the options of altering the etching process with the objective of avoiding the formation of the needle-like structures are presented and the origin of the needle-like structures is discussed.
\end{abstract}

\section{Introduction}

Metallographic preparation is a standard procedure during microstructural investigation of Ni-Ti alloys. Several phenomena like stress induced martensite or ghost martensite are known to complicate concise interpretation of the microstructure [1]. Their origin has been documented in the literature.

In recent years various authors presented micrographs of NiTi microstructures showing needle-like structures that are interpreted as martensite [2-6]. Surprisingly these needle-like structures even occurred after chemical etching on NiTi that was stated as pseudo elastic (arch wire) and thus should be in an austenitic condition [5]. Upon closer examination there are several features that contradict an interpretation of the needle-like structures as martensite, particularly rounded edges, changes in orientation that have no connection with the crystallography of the underlying grains, and the absence of grain boundaries. In the cases where details on the preparation route are described in the literature, etching solutions containing HF were applied after grinding and polishing.

In the present work the preparation route that causes or avoids the occurrence of the needle-like structures is investigated using different etching solutions containing HF. NiTi in martensitic and austenitic condition is prepared and etched. The details of the microstructure that contradict an interpretation as martensitic structure are discussed. To reveal the origin of the needle-like structures, grazing incidence X-ray diffraction is applied for analyzing the phases on the surface of NiTi after the etching process.

\section{Experimental}

NiTi in the martensitic cold deformed, austenitic cold deformed, martensitic recrystallized, austenitic straight annealed and austenitic recrystallized conditions, respectively, were investigated. The cold deformed and straight annealed materials are commercially available (Memory Metalle $\mathrm{GmbH}$ ) in form of wires and sheets in austenitic (pseudo elastic) condition with $\sim 50.8 \mathrm{at} \% \mathrm{Ni}$ and in martensitic (shape memory) condition with $\sim 49.8$ at. $\%$ Ni. The samples were recrystallized in house by annealing at $850^{\circ} \mathrm{C}$ for $1 \mathrm{~h}$.

All samples were mechanically ground and polished to a final polishing step with a suspension containing $0.25 \mu \mathrm{m} \mathrm{Al}_{2} \mathrm{O}_{3}$ particles. For chemical etching two different solutions containing HF (Table 1) were used. Etching periods varied from $\sim 3 \mathrm{~s}$ to $30 \mathrm{~s}$.

\footnotetext{
${ }^{a}$ e-mail: Andreas. Undisz@uni-jena. de
}

This is an Open Access article distributed under the terms of the Creative Commons Attribution-Noncommercial License (http://creativecommons.org/licenses/by-nc/3.0/), which permits unrestricted use, distribution, and reproduction in any noncommercial medium, provided the original work is properly cited. 
Table 1. Composition of the etching solutions (values in $\mathrm{ml}$ ).

\begin{tabular}{lcc}
\hline & etching solution 1 & etching solution 2 \\
\hline $\mathrm{HF}$ & 10 & 10 \\
$\mathrm{HNO}_{3}$ & 60 & 40 \\
$\mathrm{CH}_{3} \mathrm{COOH}$ & 30 & - \\
$\mathrm{H}_{2} \mathrm{O}$ & - & 50 \\
\hline
\end{tabular}

After the etching the samples were inspected by optical microscopy mainly in the differential interference contrast (DIC) modus and by scanning electron microscopy (SEM). To investigate the composition on the phase of the needle-like structures energy dispersive X-ray (EDX) and grazing incidence X-ray diffraction were applied to the samples before and after etching. For the grazing incidence X-ray analysis the angle between sample surface and beam was set to $3^{\circ}$ with a step width of 0.02 degrees and a measurement time of $5 \mathrm{~s}$ to $8 \mathrm{~s}$ for each step.

\section{Results and Discussion}

\subsection{Occurrence of the needle-like structures depending on the etching solution and parameters}

The two different etching solutions yield significant differences in the resulting surface structures. While etching of a martensitic recrystallized NiTi sheet with solution 1 (concentrated acid) lead to the formation of the needlelike structures immediately (Fig. 1a), etching with solution 2 (water diluted) produced clearly visible details of the microstructure like grain boundaries (Fig. 1b).

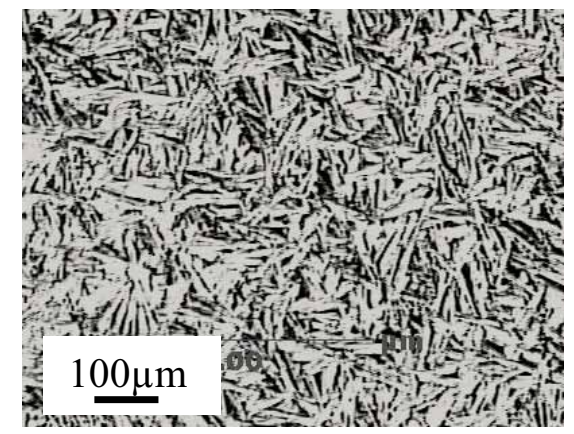

a)

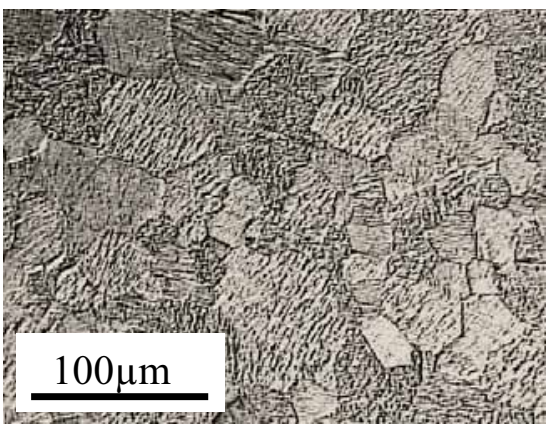

b)

Fig. 1. NiTi sheet (martensitic, recrystallized) after etching in (a) solution 1 for 10 s, with needle-like structures, and (b) solution 2 for $7 \mathrm{~s}$, with distinct grain boundaries.

Stepwise etching of a NiTi wire (austenitic recrystallized) with solution 2 (Fig. 2a) and afterwards with solution 1 (Fig. 2b) exhibits both the grain structure and the needle-like structure. From Fig. 2 b it is obvious that the needle-like structure cannot originate from martensite, since it extends over the grain boundaries without changing orientation. There is no connection of the needle-like structure and the crystallography of the grains that is to be expected for martensite needles.

The fact that the needle-like structures are visible on the surface of one sample at the same time as the grain structure in Fig. 2b shows clearly the needle-like structures are surface structures and do not originate from nor display the bulk structure. Apparently the material that is dissolved during etching re-segregates on the surface of the sample immediately. 


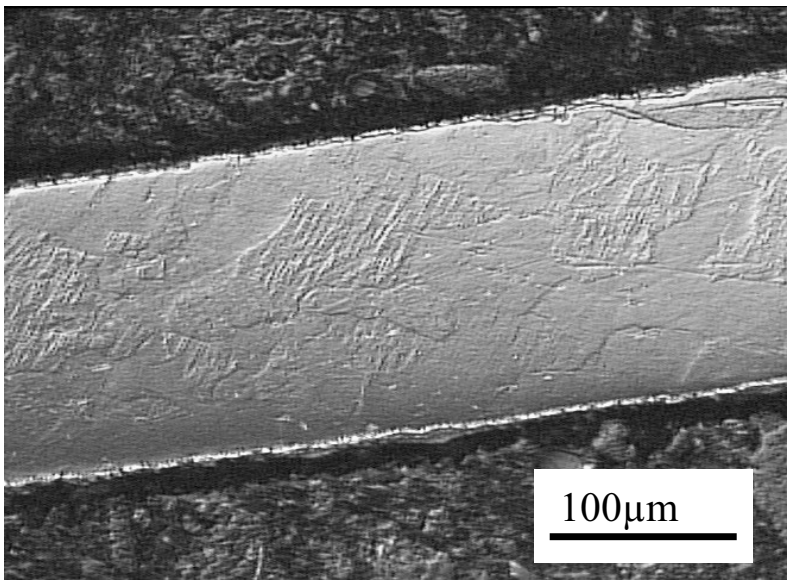

a)

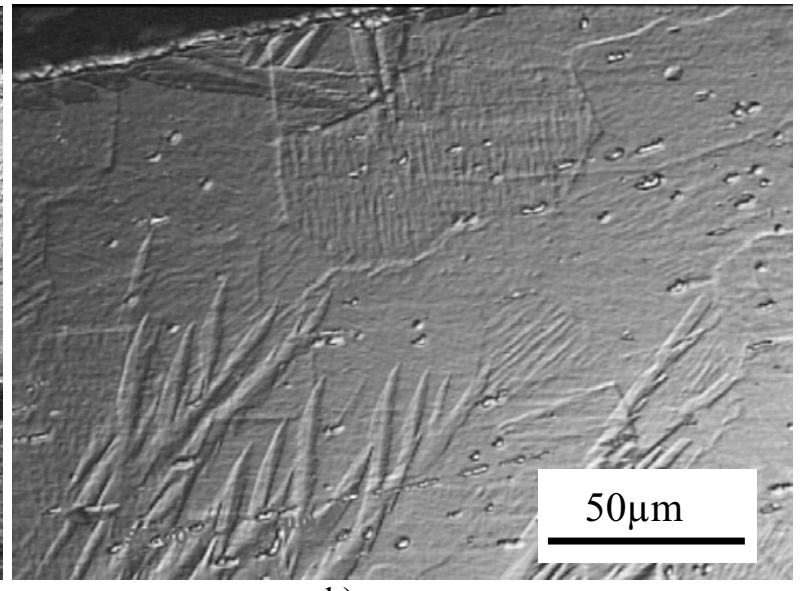

b)

Fig. 2. NiTi wire (austenitic, recrystallized) after (a) etching in solution 2 for $5 \mathrm{~s}$ with grain structure and (b) additional subsequent etching with solution 1 for 10 s with both needle-like structures and grain boundaries.

In the following investigation with the aim of identifying the origin of the needle-like structures only etching solution 1 was used. The needle-like structures emerged at the surfaces of all samples, independently of the crystal structure of the underlying phase and the adopted annealing procedure. Some of the samples were fully covered with the needle-like structure after etching, while on other samples the structures were only visible locally. The area fraction of the surface that was covered with the needle-like structures did not correlated with the duration of the etching process. A series of polishing and etching experiments showed that full coverage with the needle-like structures is attained, if etching is done without delay after the last polishing step (Fig. 3), while etching after several hours or days produces only partial coverage (Fig. 4). This is attributed to the selfpassivation of NiTi that attenuates the etching/re-segregation processes. To identify the needle-like structures in more detail, further investigations were carried out to determine their composition and their crystallographic structure.

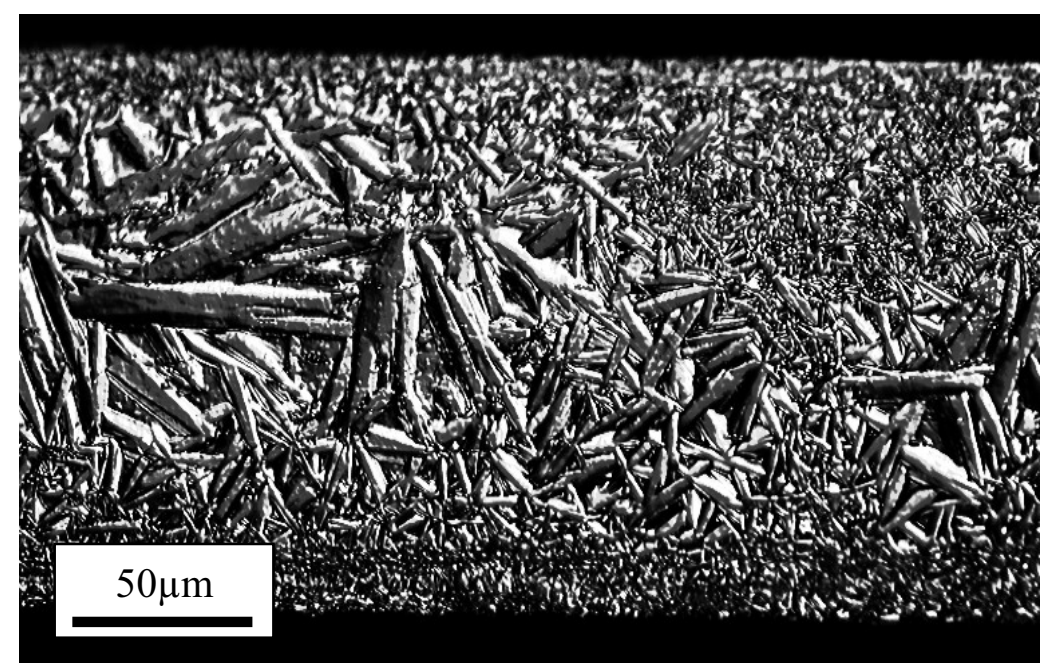

Fig. 3. NiTi wire (austenitic straight annealed) after grinding, polishing and etching for $7 \mathrm{~s}$ in solution 1 . The surface of the sample is fully covered with the needle-like structures. Etching was carried out immediately after polishing. 


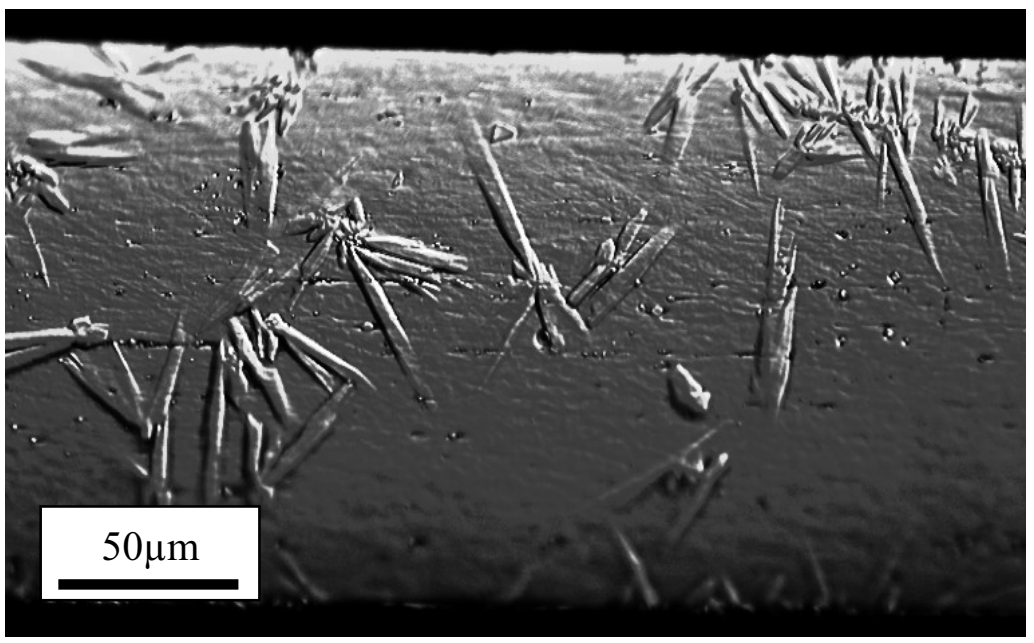

Fig. 4. NiTi wire (austenitic straight annealed) after grinding, polishing and etching for $7 \mathrm{~s}$ in solution 1 . The surface of the sample is only partially covered with the needle-like structures. Etching was carried out after an interval of several hours after polishing.

\subsection{Origin of the needle-like structures}

As mentioned above, EDX analysis is not appropriate to determine the composition of the surface needles. Reason is the penetration depth of the electron beam, which is higher than the layer thickness, and the fact that the re-deposited material consists of the etched material itself.

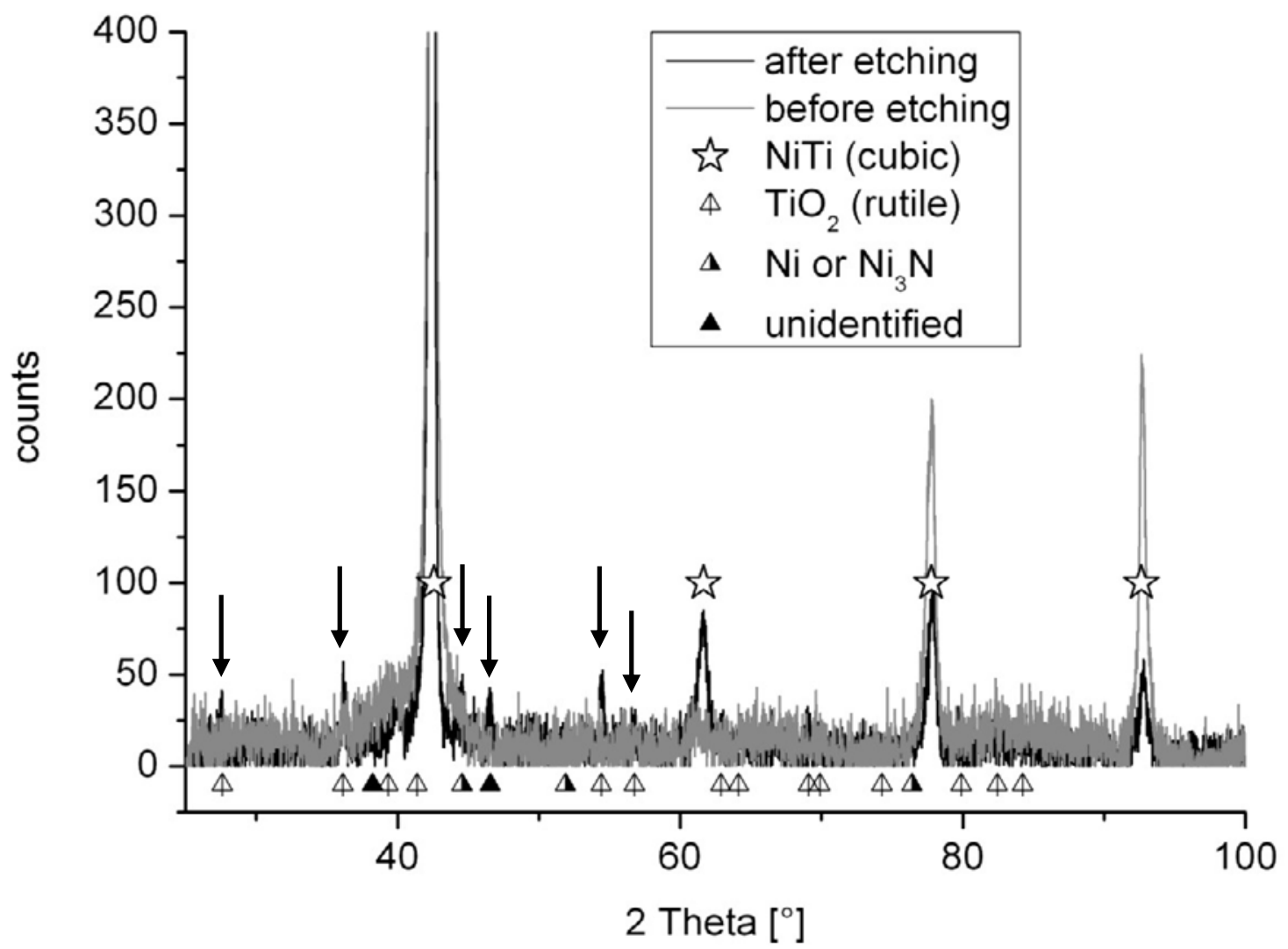

Fig. 5. Grazing incidence XRD spectra of two NiTi sheets (austenitic, recrystallized) after polishing and after polishing and subsequent etching with solution 1, respectively. The major peaks correspond to the cubic austenitic NiTi phase. Additional peaks (marked by black arrows) indicate the presence of $\mathrm{TiO}_{2}$ (rutile), a variant of hydrogen titaniumoxide hydrate (marked as 'unidentified') and of $\mathrm{Ni}$ (cubic) or/and $\mathrm{Ni}_{3} \mathrm{~N}$. 
For a detailed analysis of the phases in the surface layer, grazing incidence X-ray diffractions was applied. In Fig. 5 for both an austenitic recrystallized NiTi sample after polishing (grey) and for a sample treated with the same parameters, but with additional etching after polishing (black) are shown in superposition. The peaks corresponding to the cubic austenitic NiTi phase are identical for both samples and confirm that there is no martensite on the surface. Thus, a martensitic origin of the needle-like structures can be excluded.

In addition to the distinct austenitic NiTi peaks, further peaks were detected on the etched sample, exclusively. Four of the additional peaks are attributed to $\mathrm{TiO}_{2}$ in the rutile modification. One of the peaks matches with fcc $\mathrm{Ni}$ or $\mathrm{Ni}_{3} \mathrm{~N}$. A clear identification is impossible since the peaks of both phases are at the same $2 \theta$ position. One of the additional peaks is difficult to assign to a phase since it matches different variants of hydrogen titaniumoxide hydrates, particularly $\mathrm{H}_{2} \mathrm{Ti}_{5} \mathrm{O}_{11} \cdot 3 \mathrm{H}_{2} \mathrm{O}$ and $\mathrm{H}_{2} \mathrm{Ti}_{5} \mathrm{O}_{11} \cdot \mathrm{H}_{2} \mathrm{O}$. Evidently the re-deposited layer on the surface of the samples after etching consists of a mixture of $\mathrm{Ni}$ and $\mathrm{Ti}$ from the base material with hydrogen, nitrogen and oxygen from the etching solution.

The extraordinarily fast formation of stable $\mathrm{TiO}_{2}$ in the rutile modification during etching in less than $10 \mathrm{~s}$ is unexpected. Rutile typically forms during annealing at elevated temperatures. It is supposed that rutile is not forming directly during etching, but is converted from the less stable and defective Ti and oxygen containing compounds like the hydrogen titaniumoxide hydrates. The conversion of the components to rutile appears to be time dependent, or activated/accelerated by the X-ray beam, since longer measurements times with grazing incidence X-ray did enhance the peaks of rutile on the cost of the peaks corresponding to the hydrogen titaniumoxide hydrates. The mechanism of $\mathrm{TiO}_{2}$ formation is not clear, but it appears possible that the available $\mathrm{Ni}$ acts as catalyst during the reaction.

\section{Conclusions}

From the results of the present work it can be concluded that the needle-like structures found after etching with concentrated HF containing solutions are not martensitic and have to be regarded as artefacts. To avoid the needle-like structures and produce the microstructure of NiTi, only diluted etching solutions with HF should be applied.

\section{References}

1. E. Hornbogen, Praktische Metallographie-Practical Metallography 42(9), p. 445 (2005)

2. G.F. Vander Voort, Advanced Materials \& Processes 167(4), p. 51 (2009)

3. J.M. Gallardo, et al., Praktische Metallographie- Practical Metallography 36, p. 594 (1999)

4. S.B. Raz and S.K. Sadrnezhaad, Praktische Metallographie- Practical Metallography 42(9), p. 454 (2005)

5. M.S. Darabara et al., Journal of Biomedical Materials Research Part B 81B(1), p. 126 (2007)

6. H. Scherngell and A.C. Kneissl, Acta Materialia 50(2), p. 327 (2002) 